\section{Enquadramentos de transgênicos nos jornais paulistas: informação como potencial subsídio à participação política}

\section{The framing of transgenics in São Paulo newspapers: the potential contribution of information to political participation}

\section{Danilo Rothberg}

Professor do Departamento de Ciências Humanas/Faculdade de Arquitetura, Artes e Comunicação/Universidade Estadual Paulista Avenida Engenheiro Luiz Edmundo Carrijo Coube, 14/01 17033-360 - Bauru - SP - Brasil danroth@uol.com.br

Danilo Brancalhão Berbel

Mestrando do Programa de Pós-graduação em Ciência, Tecnologia e Sociedade/Universidade Federal de São Carlos

Rua Vereador Luiz Michelan Filho, 145 16670-000 - Presidente Alves - SP - Brasil danberbel@hotmail.com

Recebido para publicação em dezembro de 2008. Aprovado para publicação em março de 2010.
ROTHBERG, Danilo; BERBEL, Danilo Brancalhão. Enquadramentos de transgênicos nos jornais paulistas: informação como potencial subsídio à participação política. História, Ciências, Saúde - Manguinhos, Rio de Janeiro, v.17, n.2, abr.-jun. 2010, p.455-470.

\section{Resumo}

Em 2007, a Agência Nacional de Vigilância Sanitária promoveu uma consulta pública on line para receber contribuições à Proposta de Regulamento Técnico de avaliação de segurança de alimentos transgênicos. Este artigo descreve o contexto e os resultados da pesquisa que identificou os principais enquadramentos e agendas construídos pelos jornais Folha de S.Paulo e O Estado de S.Paulo sobre assuntos ligados ao objeto dessa consulta, a fim de avaliar a pluralidade de informações oferecidas como potencial subsídio à participação política. A cobertura jornalística enfocada se apresentou, em geral, fragmentada; 70\% das matérias ofereceram visões incompletas sobre o contexto da consulta.

Palavras-chave: mídia; democracia digital; enquadramento; transgênicos; Brasil.

\section{Abstract}

In 2007, Brazil's National Health Surveillance Agency (Anvisa) conducted an online public consultation to obtain input on its Proposed Technical Regulations for assessing the safety of transgenic food products. The article describes the context and results of a research study that identified the main ways in which the newspapers Folha de S.Paulo and $\mathrm{O}$ Estado de S.Paulo framed and addressed topics related to the subject matter of this consultation. Our goal was to evaluate the gamut of information available that could contribute to this form of political participation. The journalistic coverage in question was generally fragmented; $70 \%$ of articles offered incomplete views on the topics in question.

Keywords: media; digital democracy; framing; transgenics; Brazil. 
$\mathrm{C}$ om a popularização da internet, desenvolvem-se novas formas de decisão política. As consultas públicas on line são uma das que podem ampliar a participação da sociedade na formulação de políticas públicas. Atualmente, os websites do governo federal brasileiro já estão explorando as novas tecnologias nesse sentido, especialmente para consultar setores estratégicos na definição de políticas de saúde e meio ambiente. Destacase, nesse contexto, a consulta pública on line 63 realizada pela Agência Nacional de Vigilância Sanitária (Anvisa) ${ }^{1}$, de 11 de julho de 2007, em torno da proposta de regulamento técnico de avaliação de segurança para o consumo humano de alimentos contendo ou consistindo de organismo geneticamente modificado (OGM) e de alimentos contendo ou consistindo de produtos derivados de animais alimentados com OGM ou com seus produtos derivados.

As consultas on line são meios de construção compartilhada de políticas públicas e legislações. Setores governamentais submetem uma versão inicial do texto sob consulta pela internet, e indivíduos e setores se manifestam sobre os aspectos propostos, indicam a necessidade de mudanças, justificam suas sugestões, conhecem as contribuições de outros participantes, reveem seus conceitos após descobrir as posições alheias e combinam-se com outros para propor alterações.

A participação em consultas públicas requer conhecimentos e informações que sustentem a formulação de perspectivas e sugestões consistentes. Indivíduos e setores interessados em participar devem buscar fontes diversas de informação e interpretação, e o cenário composto pelo jornalismo nas sociedades contemporâneas ainda é relevante nesse contexto. Adicionalmente, os meios de comunicação devem ser considerados veículos de expressão de conflitos entre setores sociais diversos, de maneira que elites econômicas e políticas encontrem ali um espaço de luta simbólica, no qual procuram fazer com que suas perspectivas se tornem dominantes na esfera pública (Bourdieu, 1999; Corcuff, 2001; Davies, 2002).

Metodologicamente, na análise dos posicionamentos veiculados pelas mídias jornalísticas, é preciso considerar que as apropriações simbólicas estão associadas a discursos característicos de setores sociais, econômicos e políticos determinados (Hall, 2003). Tais discursos se associam a marcos interpretativos singulares, que podem ser identificados pela pesquisa em comunicação na forma de enquadramentos (framing) e agendas (agenda-setting) (Porto, 2004; Azevedo, 2004; Wolf, 2005).

Surgem, assim, os seguintes problemas de pesquisa: (a) quais são os enquadramentos e agendas - e os correspondentes interesses políticos e econômicos - que podem ter contribuído para subsidiar a participação na consulta em questão, considerando-se os dois principais jornais do estado de São Paulo (em relação à tiragem diária), ${ }^{2}$ no período de março de 2005, mês em que a Lei de Biossegurança (11.105, de 24 de março de 2005) foi sancionada pela Presidência da República, até setembro de 2007, mês em que foi concluída a consulta pública da Anvisa 63?; (b) quais são as semelhanças e os contrastes entre enquadramentos e agendas construídos pelos dois principais jornais do estado de São Paulo, no período em questão?

Este artigo apresenta os resultados de investigação na qual esses problemas de pesquisa se relacionaram à tarefa de identificar os principais enquadramentos e agendas construídos pelos jornais Folha de S.Paulo e O Estado de S.Paulo, de março de 2005 a setembro de 2007, a 
respeito de assuntos ligados ao objeto da consulta pública on line Anvisa 63. O propósito foi avaliar a pluralidade de informações e interpretações oferecidas pelos dois principais jornais do estado como potencial subsídio à participação política. ${ }^{3}$ Inicialmente são apresentados conceitos teóricos pertinentes, ligados às temáticas de democracia digital, agenda e enquadramentos midiáticos. Em seguida, os resultados da pesquisa em questão são caracterizados e discutidos. Como conclusão, as considerações finais sintetizam as principais percepções obtidas pelo estudo.

Pode-se indicar que, mesmo com uma cobertura fragmentada e que tendeu a enquadrar majoritariamente os OGMs de maneira favorável - o que confronta os princípios éticos de pluralidade e equilíbrio necessários à atividade jornalística -, a Folha de S.Paulo e O Estado de S.Paulo ofereceram subsídios relevantes à participação política e figuram como fontes de informação para a compreensão de complexas temáticas referentes ao desenvolvimento sustentável na atualidade. No entanto, cerca de 70\% das 163 matérias analisadas no estudo ofereceram visões incompletas sobre o contexto da consulta pública.

\section{Democracia digital}

Uma percepção comum entre os cientistas sociais é a de que as práticas democráticas e as formas institucionais de representação política enfrentam um contexto de crise. Trata-se de uma crise "de um padrão simbólico da experiência democrática que pretende que o cidadão ... seja aquele que governe", indica Gomes (2005, p.217).

A participação civil estaria restrita ao ato de eleger representantes e reservar a eles o poder da decisão política. A distância entre as esferas civil e política assumiria grandes proporções. Daí o advento das novas tecnologias de informação e comunicação (TICs) representar uma possibilidade de superação desse quadro e fazer ressurgirem as "esperanças de modelos alternativos de democracia que implementem uma terceira via entre a democracia representativa, que retira do povo a decisão política, e a democracia direta, que a quer inteiramente consignada ao cidadão", sustenta Gomes (2005, p.218).

Conforme avançam as tecnologias, práticas de governo são modernizadas. Na gestão pública, as formas de democracia eletrônica são tidas como promissoras. "A internet é tomada, por diferentes autores, como uma espécie de 'revigorante' da esfera pública política argumentativa", indica Marques (2006, p.167). O potencial do meio viria de duas formas: em primeiro lugar, se "concede oportunidade de expressão a vozes marginais, sem as barreiras impostas pela censura governamental ou pelos interesses das indústrias do entretenimento e da informação"; em segundo, se oferece "a chance da reciprocidade discursiva advinda da esfera civil" (p.167).

Recentemente, multiplicaram-se as consultas públicas on line no Brasil sobre temas como a Política Nacional de Atenção Integral à Saúde de Adolescentes e Jovens; a Proposta de Regulamento Técnico de publicidade de alimentos com quantidades elevadas de açúcar, de gordura saturada, de gordura trans, de sódio e de bebidas com baixo teor nutricional; e a Proposta de Regulamento Técnico de avaliação de segurança para o consumo humano de alimentos contendo ou consistindo de organismo geneticamente modificado (OGM) e 
de alimentos contendo ou consistindo de produtos derivados de animais alimentados com OGM ou com seus produtos derivados.

Uma vez que tais consultas têm o potencial de ampliar a esfera pública deliberativa, passa a ser relevante avaliar como as fontes de informação jornalística podem subsidiar a participação política. Afinal, a disponibilidade de informação tem sido considerada peça fundamental para o aperfeiçoamento democrático. "Um ponto de estrangulamento importante, quando se pensa no aprofundamento das democracias contemporâneas, é a difusão da informação", assinala Miguel (2004, p.130). O autor afirma o papel da pluralidade na provisão de informação política: o que deve diferenciar a informação em uma democracia é sua natureza plural. "As diferentes perspectivas e visões de mundo devem estar disponíveis para o conjunto de cidadãs e cidadãos" (p.130-131).

Os mecanismos de agenda-setting e enquadramento, dominantes no campo midiático e resultado da expressão de perspectivas específicas pelos meios jornalísticos, não podem ser ignorados nesse contexto, porque representam potenciais limitações à oferta de subsídios para a participação política.

\section{Agendas e enquadramentos}

A hipótese de agenda-setting sustenta pesquisas que investigam a agenda da mídia a fim de identificar as maneiras pelas quais ela influenciaria a agenda do público. Segundo tal conceito, o público tende a conferir importância a temas que refletem de perto a ênfase atribuída pelos meios de comunicação de massa a acontecimentos, problemas e pessoas.

Segundo Azevedo (2004, p.52), a mídia, "ao adotar enquadramentos positivos ou negativos sobre os temas, acontecimentos e atores, constrói atributos (positivos ou negativos) sobre esses objetos". Por sua vez, Wolf (2005) indica que a ação da mídia sobre as pessoas influencia a percepção que elas tendem a possuir sobre a ordem das questões mais importantes em dado momento. São os temas que os meios de comunicação relacionam como relevantes para os receptores. Haveria, segundo o autor, dois níveis de atuação nesse sentido: " $a$. a 'ordem do dia' dos temas, argumentos, problemas, presentes na agenda da mídia; $b$. a hierarquia de importância e de prioridade com que esses elementos estão dispostos na 'ordem do dia'” (p.146).

É consenso entre os pesquisadores de comunicação que os jornalistas não conseguem atingir as almejadas objetividade e imparcialidade em seu trabalho, devido às escolhas que fazem ao produzir as matérias. A seleção resulta em determinados enquadramentos dos acontecimentos: "tendemos a perceber os eventos e as situações de acordo com enquadramentos que nos permitem responder à pergunta: 'o que está acontecendo aqui?'” - sintetiza Porto (2004, p.78); "enquadramentos são entendidos como marcos interpretativos mais gerais construídos socialmente, que permitem às pessoas fazer sentido dos eventos e das situações sociais" (p.78).

Para Entman (1993), enquadramento envolve seleção e ênfase: "enquadrar é selecionar alguns aspectos da realidade percebida e torná-los mais salientes num texto comunicativo, de forma a promover uma definição particular de um problema, uma interpretação causal, avaliação moral e/ou recomendação de tratamento" (p.52). 
Porto (2004) afirma que "além de constituir um paradigma alternativo à abordagem da objetividade, o conceito de enquadramento tem contribuído também para dinamizar perspectivas teóricas existentes, particularmente as pesquisas sobre a função de agendamento na mídia ou agenda-setting" (p.76). Nesse contexto, a formação de agenda corresponderia a um primeiro nível de efeitos, ao passo que o enquadramento exerceria o papel de um segundo nível. Sobre o primeiro nível, entende-se o estudo 'sobre o que' o público pensa; o segundo nível faz referência a 'como' o público pensa.

É possível compreender como enquadramento o formato escolhido para determinada transmissão de mensagem. É o recorte efetuado na transmissão de uma mensagem, de acordo com os entendimentos do seu idealizador. O enquadramento proporciona interpretações dos fatos, sem que a opinião do emissor da mensagem esteja necessariamente explícita. "Enquadramentos são entendidos como recursos que organizam o discurso através de práticas específicas (seleção, ênfase, exclusão) e que acabam por construir uma determinada interpretação dos fatos" (Porto, 2004, p.80).

Entman (1993) assinala quatro aspectos relevantes para compreender o conceito de enquadramento: autonomia da audiência; objetividade jornalística; análise de conteúdo; e relações entre opinião pública e teoria do modelo democrático'. Subjacente à ideia de autonomia da audiência está o reconhecimento de que a audiência possui suas próprias maneiras de decodificar os textos jornalísticos, de forma que os significados veiculados pela mídia podem ser reelaborados pelo público. No entanto, a despeito do caráter independente da recepção, certos significados podem prevalecer, de acordo com uma perspectiva "com maior probabilidade de ser noticiada, processada e aceita pela maioria das pessoas" (p.56).

Sob o conceito de objetividade jornalística está a percepção de que, mesmo que o jornalista siga as regras profissionais que exigem a produção de reportagens objetivas, seu texto carregará um enquadramento dominante. Para o autor, inclusive, é necessário que o jornalista seja treinado para perceber a influência de valores individuais, editoriais e de classe sobre a produção de enquadramentos implícitos em sua matéria. Já a análise de conteúdo passa a ser entendida como busca de enquadramentos: "a maior tarefa de determinar o significado textual deve ser identificar e descrever enquadramentos" (Entman, 1993, p.57).

As técnicas usuais de análise de conteúdo são vistas com reserva por Entman (1993) porque, ao considerar apenas o somatório das ocorrências de uma unidade linguística em um texto, deixariam escapar significados importantes decorrentes da ênfase sobre determinados aspectos.

Por fim, ao focar as relações entre opinião pública e teoria do modelo democrático, Entman (1993) aponta o risco de o processo democrático ser determinado pelo poder central do enquadramento, que influencia a formação da opinião pública. Esse contraponto levanta questionamentos sobre a legitimidade democrática e coloca em xeque o conhecimento advindo de levantamentos de opinião pública. "Se, através da formatação de enquadramentos, as elites podem determinar as principais manifestações da 'verdadeira' opinião pública disponível ao governo (através de pesquisas ou do voto), o que pode ser a verdadeira opinião pública?", questiona Entman (p.57). "O paradigma do enquadramento pode iluminar, isso se não resolver, tais enigmas centrais na teoria democrática normativa" (p.57). 
Danilo Rothberg, Danilo Brancalhão Berbel

A maior parte da influência econômica e cultural sobre as mensagens jornalísticas teria origem no pensamento das elites. Isso porque, segundo Carragee e Roefs (2004), há tendência de os repórteres concederem mais credibilidade a fontes oficiais, bem como grande parte do noticiário buscar órgãos do governo como fontes.

Para Reese (2007), os enquadramentos são compartilhados socialmente e persistem ao longo do tempo na forma de "estruturas que desenham limites, constroem categorias, definem algumas ideias como excludentes e incluem outras, e, geralmente, operam a fim de entrelaçar ideias relacionadas em suas teias em um processo ativo" (p.150).

\section{Amostra e métodos}

A amostra de análise foi constituída por 163 matérias, editoriais e artigos publicados pelos jornais O Estado de S. Paulo e Folha de S.Paulo entre março de 2005, mês em que foi aprovada a Lei de Biossegurança, que trouxe uma nova política ao setor, e setembro de 2007, quando se encerrou a consulta pública on line Anvisa 63, sobre assuntos ligados ao consumo humano de alimentos contendo ou consistindo de organismo geneticamente modificado (OGM) e de alimentos contendo ou consistindo de produtos derivados de animais alimentados com OGM ou com seus produtos derivados.

Os textos foram selecionados nas páginas dos jornais na internet, por meio de busca dos termos 'transgênico' e 'transgênicos'. Assim, analisaram-se os textos publicados no período que podem ter contribuído para formar posicionamentos gerais sobre a temática em questão, inclusive de indivíduos e setores interessados em participar da consulta pública Anvisa 63. Essa análise foi realizada por meio da construção de quadros que relacionaram seleção, ênfase e exclusão de informações e interpretações, gerando uma base de dados que permitiu a identificação e análise de enquadramentos e agendas veiculados pelos jornais enfocados, sobre a temática em questão.

A descrição de enquadramento exige a identificação de três componentes essenciais: seleção; ênfase; e exclusão de informações relativas a questões, fatos e acontecimentos enfocados (Entman, 1993, 2007; Porto, 2004).

A seleção de informações operada por um texto pode ser apreendida com a identificação e descrição das principais temáticas ali relacionadas, considerando-se que as escolhas efetivas ocorreram dentro de uma gama possível de opções. Dessa forma, a simples presença de certas temáticas, em um dado texto, já é indicador de tendências de valorização de certas questões, o que no médio e longo prazos pode contribuir para o surgimento e fortalecimento de tendências políticas, econômicas e sociais. Além disso, certas temáticas se relacionam a determinados setores sociais e instituições políticas, o que permite estimar a associação entre enquadramentos e interesses políticos e econômicos.

A ênfase de informações em um texto pode ser apurada com a identificação e descrição dos significados presentes nos elementos de mais destaque, como título, introdução e pontos estratégicos salientados pelos elementos de progressão textual. A ênfase assim identificada se relaciona às perspectivas simbólicas centrais afirmadas por um texto; portanto, as relações de poder simbólico contidas em uma manifestação discursiva podem ser 
apreendidas a partir do estudo dos elementos ali enfatizados, por meio de recursos de construção de sentido.

A identificação das informações excluídas de um texto exige relacionar, em primeiro lugar, aspectos que, em virtude do foco adotado, das temáticas selecionadas e da ênfase detectada, seriam necessários para permitir uma compreensão abrangente do fato ou acontecimento em questão, com seus aspectos intrínsecos nas dimensões política, social e econômica. Em seguida, em contraste entre tal relação e o conjunto de informações efetivamente apresentado pelo texto, podem-se identificar os conteúdos que permaneceram ausentes. Novamente, como certas temáticas se relacionam a determinados setores sociais, a exclusão de determinadas questões pode apontar a prevalência de interesses políticos e econômicos na formação de enquadramentos.

\section{Resultados e discussão: perspectivas simbólicas, política pública e interesses}

O regulamento submetido à consulta pública Anvisa 63 foi proposto para subsidiar a "análise a ser feita pela Anvisa nos processos oriundos da CTNBio, como subsídio à Comissão de Biossegurança em Saúde do Ministério da Saúde", segundo seu artigo 1‥ Ele serviria para embasar procedimentos de verificação de segurança na avaliação de pedidos de liberação para uso comercial de transgênicos, não sendo cabível para avaliação de outros pedidos de aprovação, como os de pesquisas científicas envolvendo OGMs.

O regulamento enfatiza a necessidade de um "constante aperfeiçoamento das ações de vigilância sanitária na área de alimentos, visando à proteção à saúde da população" e a necessidade de "criar mecanismos visando à avaliação de segurança para o consumo humano de alimentos contendo ou consistindo de OGM ou de seus derivados".

A consulta indica a preocupação da Anvisa com a segurança alimentar, que poderia ser colocada em risco por transgênicos liberados sem a devida avaliação. Nesse contexto, a Anvisa sugere que a forma como as deliberações estariam sendo conduzidas pela Comissão Técnica Nacional de Biossegurança (CTNBio) ${ }^{4}$ poderia não ser a mais adequada, o que tornaria necessária a criação do Regulamento. O objetivo seria instituir "procedimentos para avaliação de segurança de alimentos para o consumo humano, contendo ou consistindo de OGM ou de seus derivados", de maneira que a análise seria "feita pela Anvisa nos processos oriundos da CTNBio".

A Lei de Biossegurança prevê que outros órgãos estejam envolvidos nos processos de deliberação, oferecendo subsídios para que os membros da CTNBio analisem e decidam sobre a aprovação de pedidos relacionados a transgênicos. A proposta da Anvisa era que o Regulamento Técnico servisse como subsídio para avaliação de OGMs por parte da própria agência, com a função de fundamentar o deferimento ou indeferimento de pedidos que não correspondessem às exigências presentes no documento.

A Anvisa realizaria sua avaliação antes mesmo da CTNBio, o que lhe conferiria poderes sobre a deliberação de transgênicos, com a possibilidade de justificar um possível indeferimento de pedidos de liberação comercial de OGMs antes que chegassem à alçada da Comissão. O indeferimento ocorreria caso fossem apresentados dados incompletos, não válidos ou insuficientes para sustentar a segurança de uso do alimento para o consumo 
humano e caso se chegasse à conclusão de que a modificação genética não teria atingido o objetivo proposto.

O regulamento não eximiria um pedido de passar por processos de aprovação da CTNBio ou outros órgãos que subsidiassem a deliberação. E, mesmo aprovado pela Anvisa, o pedido de liberação poderia ser indeferido pela Comissão.

A consulta apresentou um roteiro de 119 perguntas referentes a cinco eixos: questões relativas à modificação genética; questões relativas ao organismo receptor; questões relativas à segurança alimentar aplicáveis ao organismo receptor e ao OGM; questões relativas à segurança de alimentos contendo ou consistindo de microrganismo geneticamente modificado; e questões relativas à qualidade nutricional.

Os 163 textos publicados entre março de 2005 e setembro de 2007 pelos jornais Folha de S.Paulo e $O$ Estado de S.Paulo sobre a temática dos transgênicos possuem informações e enquadramentos que podem ter contribuído para subsidiar a participação política em torno dos cinco eixos propostos pela consulta pública 63 .

O jornal Folha de S.Paulo cobriu a temática em questão principalmente através das editorias de Economia e Ciência. O veículo publicou sessenta matérias informativas sobre o assunto no período analisado, das quais $70 \%$ no caderno Dinheiro. O caderno Ciência publicou $26,7 \%$ das matérias sobre o assunto; $1,6 \%$ das matérias foi publicado no caderno Brasil. Foram 23 textos opinativos, sendo nove editoriais e 14 artigos.

O jornal O Estado de S.Paulo publicou 75 matérias informativas sobre a temática em questão no período analisado. Destas, 77,3\% foram veiculadas no caderno Cidades. O caderno Vida \& Meio Ambiente publicou 8\% das matérias, seguido pelos cadernos Economia, com 6,7\% das publicações; Vida \&, com 5,3\%; Vida \& Ciência e Suplementos/Agrícola, com 1,3\% cada. Foram cinco textos de gênero opinativo, sendo dois editoriais e três artigos.

Duas perspectivas se destacam na cobertura sobre transgênicos, nos jornais Folha de S.Paulo e O Estado de S.Paulo: por um lado, um enquadramento que caracteriza os OGMs como produto do avanço tecnológico, benéficos para a economia e potencialmente capazes de solucionar problemas da sociedade como fome e desnutrição; por outro lado, em menor proporção, um enquadramento que sugere a possibilidade de transgênicos trazerem riscos à saúde humana e à biodiversidade.

Os principais enquadramentos alinhados a uma perspectiva geral favorável dos OGMs, presente em $60 \%$ dos textos informativos e $56,3 \%$ dos textos opinativos publicados pela Folha de S.Paulo e em $44 \%$ dos textos informativos e $80 \%$ dos opinativos publicados em O Estado de S.Paulo, são representados por: (a) tratamento favorável dedicado aos transgênicos, pela caracterização negativa da CTNBio por supostamente retardar as liberações comerciais de OGMs; (b) caracterização positiva da redução do quórum para votações na CTNBio, por ser necessária à suposta agilidade da Comissão para a liberação do cultivo de transgênicos no país.

Os principais enquadramentos alinhados à perspectiva geral que sugere a existência de riscos no cultivo de OGMs, presente em $20 \%$ dos textos informativos e $21,7 \%$ dos opinativos publicados pela Folha de S.Paulo, e em 36\% dos textos informativos e ausente nos textos opinativos do jornal O Estado de S. Paulo, são representados por: (a) caracterização do embargo do mercado europeu aos produtos geneticamente modificados, por ser um indicador dos 
possíveis riscos advindos do cultivo de transgênicos; (b) manifestação de organizações contrárias ao desenvolvimento dos OGMs, que sustentam a necessidade de a sociedade ter cautela diante da popularização do cultivo de transgênicos. ${ }^{5}$

A consulta pública on line 63 da Anvisa foi especificamente tratada apenas pelo jornal O Estado de S.Paulo, com enquadramentos bastante críticos, os quais se somam ao conjunto das perspectivas sobre o avanço dos transgênicos no Brasil, que, difundidas pelos jornais analisados, podem de maneira geral ter influenciado a formação de posicionamentos relevantes em torno do assunto, inclusive dos setores interessados em participar da consulta em questão.

\section{Semelhanças e contrastes}

Comparado a O Estado de S.Paulo, a Folha de S.Paulo publicou porcentagem maior de matérias com enquadramentos que contribuem para a construção de uma agenda favorável aos transgênicos: $60 \%$ contra $44 \%$. Textos caracterizados por enquadramentos sobre os possíveis riscos que os OGMs poderiam causar à saúde humana e à biodiversidade tiveram mais espaço entre as matérias de O Estado de S.Paulo, somando 36\%. A Folha de S.Paulo dedicou $20 \%$ a essa perspectiva. O Estado de S.Paulo apresentou mais equilíbrio, nos textos informativos publicados, entre as perspectivas principais identificadas na cobertura dos jornais sobre a temática dos transgênicos.

Já entre os textos de gênero opinativo, a Folha de S.Paulo apresentou relação semelhante com respeito às matérias informativas: $56,3 \%$ de textos favoráveis aos transgênicos contra $21,7 \%$ de textos que sugerem cautela quanto aos possíveis riscos que eles poderiam causar. O Estado de S.Paulo dedicou $80 \%$ de seus artigos e editoriais sobre a temática para um enquadramento favorável aos OGMs.

Os outros $20 \%$ do jornal O Estado de S.Paulo se referiram à consulta pública on line 63 da Anvisa, que foi caracterizada de maneira desfavorável. No cenário apresentado pelo jornal, a proposta da Anvisa de estabelecer "normas para avaliação da segurança de transgênicos" é caracterizada como um problema para o governo e estaria gerando uma crise de poderes entre a Anvisa e a CTNBio.

A proposta da Anvisa foi enquadrada pelo jornal O Estado de S.Paulo como prejudicial ao desenvolvimento dos transgênicos, porque dificultaria sua liberação comercial, já que instituiria um processo de verificação de segurança de OGM referenciado em um complexo questionário de 119 questões. Segundo o enquadramento do jornal, o processo ficaria ainda mais moroso; a CTNBio se tornaria uma mera instância homologadora das decisões provenientes dos resultados do questionário.

Os textos excluem informações sobre, por exemplo, a possível contribuição que o roteiro de perguntas traria para a verificação de segurança dos OGMs e para a identificação de riscos de determinadas variedades encaminhadas com solicitação de aprovação comercial à Comissão.

$\mathrm{Na}$ avaliação da qualidade das informações na amostra analisada, uma questão relevante é a pluralidade de fontes. A falta de pluralidade pode comprometer a qualidade da informação, tornando a notícia fragmentada e, portanto, contribuindo de maneira insufi- 
ciente como subsídio para a participação política, como no caso da consulta pública que foi objeto desta pesquisa. A Folha de S.Paulo se caracterizou por ausência de pluralidade em $63,3 \%$ de suas matérias informativas analisadas e O Estado de S.Paulo, em 74,7\% de suas matérias, o que se manifesta na criação de contextos fragmentados sobre a temática, possivelmente prejudicando a formação do leitor. Perspectivas relevantes para uma compreensão abrangente do assunto não são apresentadas com clareza e equilíbrio, ou são excluídas do enfoque jornalístico, que assim promove agendas e enquadramentos específicos, majoritariamente de setores que defendem a difusão dos OGMs.

De acordo com a Folha de S.Paulo, a agenda favorável aos transgênicos se justifica principalmente devido aos supostos benefícios para a humanidade que os OGMs trariam e ao avanço das plantações de transgênicos no Brasil e no mundo. Conforme os enquadramentos majoritariamente construídos pelo jornal, os alimentos geneticamente modificados representariam avanços científicos e não haveria riscos à saúde humana.

O Estado de S.Paulo sustenta uma agenda favorável aos OGMs, de maneira a endossar o apoio que eles teriam recebido de setores do governo, com enquadramentos que caracterizam de forma positiva o desempenho da produção brasileira de transgênicos e sustentam as expectativas de sua liberação para cultivo e comercialização. Segundo esse cenário, o governo estaria incentivando o plantio de OGMs ao trocar sementes não certificadas dos produtores por sementes legalizadas.

Outra agenda presente na cobertura da Folha de S.Paulo e de O Estado de S.Paulo sobre a temática dos transgênicos foi construída com enquadramentos desfavoráveis à CTNBio. A Folha de S.Paulo a caracteriza como morosa na deliberação sobre os transgênicos e como órgão que sofre interferências externas no exercício de suas funções. Os textos de gênero opinativo da Folha de S.Paulo chegam a considerar a Comissão um órgão paralisado. O Estado de S.Paulo constrói agenda semelhante, enfatizando que a CTNBio seria incapaz de deliberar sobre transgênicos. ${ }^{6}$

A preocupação dos jornais acerca do período supostamente excessivo para a CTNBio deliberar sobre um OGM é justificada da seguinte maneira: se a Comissão liberasse transgênicos para uso comercial, isso seria um sinal de que estaria funcionando bem. $\mathrm{O}$ fato de não ter aprovado efetivamente nenhuma variedade transgênica no período de dois anos significaria que ela não seria competente para executar as funções para as quais foi criada.

De acordo com a agenda de ambos os jornais a respeito do assunto - principalmente por ambos terem publicado editoriais que o evidenciam -, a CTNBio funcionaria bem se fosse imune às interferências de ONGs contrárias aos transgênicos - por diversas vezes, caracterizadas como inimigas do progresso - e tivesse um quórum mais flexível para aprovação, de modo a facilitar o alegado progresso da biotecnologia no país.

Nesse contexto, a redução do quórum da CTNBio para deliberação dos transgênicos é caracterizada favoravelmente por ambos os jornais. A medida é considerada a solução para o suposto entrave estabelecido pela Comissão. Os jornais não levam em consideração argumentos de opositores à redução do quórum, segundo os quais um número maior de membros seria importante para o processo de deliberação segura sobre OGMs.

A Folha de S.Paulo apresentou agenda desfavorável à rotulagem explícita dos transgênicos para exportação, com enquadramentos que sustentaram que tal medida prejudicaria a 
imagem dos OGMs, além de desfavorecer a economia do setor por tornar a produção mais dispendiosa. O Estado de S.Paulo enquadrou o assunto de maneira diferente. De acordo com esse jornal, seria importante para o desenvolvimento dos OGMs que eles fossem devidamente rotulados, para que os importadores e consumidores tivessem consciência do que estão comprando. Esse posicionamento coincide com o do governo brasileiro, que apoiou a rotulagem explícita em acordo internacional assinado por 132 países.

Os possíveis riscos trazidos por OGMs são enfatizados por $20 \%$ dos textos informativos e 21,7\% dos textos opinativos da Folha de S.Paulo. Com agenda similar, O Estado de S.Paulo apresenta $36 \%$ dos informativos e nenhum opinativo. Em geral, segundo os enquadramentos analisados, os riscos seriam apontados por pesquisas científicas e experiências internacionais, ou seriam decorrência da identificação de plantações ilegais de OGMs, com sementes não avaliadas pelos órgãos competentes. Outro enquadramento que compõe a agenda que sugere cautela diante dos transgênicos se refere ao embargo europeu aos OGMs. As matérias apontam o mercado europeu como fechado aos transgênicos até que testes comprovassem sua segurança para consumo humano.

$\mathrm{Na}$ agenda dos jornais analisados sobre a temática em questão, os interesses econômicos são privilegiados em comparação aos ambientais. Os veículos de comunicação caracterizam os posicionamentos contrastantes que a temática envolve como 'agronegocistas', de um lado, e 'ambientalistas', de outro. É possível perceber o favorecimento ao primeiro grupo na cobertura de ambos os jornais. Os ambientalistas são caracterizados por argumentos pouco representativos e criticados por serem supostamente 'ideológicos', ao passo que os agronegocistas têm espaço para apresentar seus argumentos de maneira mais convincente e palpável.

Os transgênicos são tratados como avanço científico, e a preocupação ambiental gira em torno do 'princípio da precaução', utilizado por posições que seriam marcadas por falta de cientificidade e preconceito contra as novas tecnologias.

Pode-se indicar que o cenário edificado por Folha de S.Paulo e O Estado de S.Paulo sobre a temática dos transgênicos se apresenta, em ampla medida, fragmentado, favorável aos transgênicos e crítico aos opositores de sua perspectiva. Com isso, pode-se sugerir que a cobertura desses jornais poderia não ser suficiente para subsidiar, de maneira abrangente, plural e com equilíbrio entre os diversos posicionamentos em jogo, a participação política na apreciação da proposta da Anvisa.

A agenda majoritariamente construída por aqueles veículos tendeu a favorecer determinada perspectiva de apoio à expansão dos transgênicos, o que poderia fundamentar a rejeição da proposta, implícita no texto da consulta pública 63, de ampliar os poderes da Anvisa sobre as deliberações a respeito da liberação de OGMs na CTNBio. Em tese, tal perspectiva parece ter sido preponderante, contribuindo para o fortalecimento de uma tendência que pode ter influenciado o desfecho da decisão pública: o Ministério da Saúde, próximo ao final do período de consulta, anunciou que o regulamento posto sob consulta pela Anvisa não teria "poder de regras" e assumiria a função de suporte técnico somente em caráter consultivo (Bastos, 2007).

Em geral, os gestores das consultas públicas on line no Brasil, ao contrário das práticas estabelecidas por países em estágios mais avançados de democracia digital (Rothberg, 2008), 
não informam quantas nem quais contribuições foram recebidas, e não detalham como elas influenciaram os rumos da formulação de políticas públicas. Assim, pretende-se aqui indicar apenas as perspectivas da cobertura jornalística de importantes veículos que foram majoritárias no período da consulta em questão e possuíram, portanto, poder de influir sobre o debate em torno do assunto. Um estudo das contribuições transmitidas em uma consulta pública se mostra muito pertinente e deve se tornar viável no futuro, no Brasil, à medida que os gestores de consultas sejam pressionados pelos setores participantes e indiquem se as contribuições foram aproveitadas e de que maneira.

As perspectivas favoráveis aos transgênicos foram motivadas por circunstâncias diferentes em cada jornal. O Estado de S.Paulo tendeu a caracterizar positivamente os transgênicos como forma de endossar o apoio que teriam recebido de setores do governo federal. Por outro lado, a Folha de S.Paulo tendeu a privilegiar interesses do agronegócio ao construir enquadramentos favoráveis aos OGMs.

Os enquadramentos arquitetados pelos jornais que justificariam o posicionamento favorável aos OGMs ocorrem, principalmente, em duas agendas: na caracterização dos transgênicos como um avanço tecnológico capaz de desenvolver a economia do setor agrícola; e na caracterização dos transgênicos como alimentos benéficos para a humanidade, por propiciarem vantagens de crescimento da produção sem aumentar a área plantada e minimizarem problemas da humanidade como fome e desnutrição.

Os veículos de comunicação são empresas e tendem a expressar suporte a setores industriais, com objetivo de estimular o crescimento econômico. Ao favorecerem os transgênicos, estariam construindo uma agenda favorável ao avanço tecnológico e ao desenvolvimento econômico e contribuindo para a realização da política de setores do governo federal de apoio à expansão do agronegócio. De acordo com os enquadramentos identificados nos jornais analisados, o governo brasileiro teria posicionamentos antagônicos com relação aos transgênicos. Setores governamentais estariam interessados no avanço tecnológico, desenvolvimento econômico e outros benefícios que os OGMs alegadamente ofereceriam. O Ministério da Agricultura, Pecuária e Abastecimento é um exemplo de órgão governamental que apoiaria essa perspectiva. Mas outros setores do governo teriam posicionamento contrário ao desenvolvimento dos transgênicos, devido aos possíveis riscos à saúde e ao meio ambiente que eles ofereceriam, como o Ministério do Meio Ambiente e o Ibama. A própria CTNBio estaria paralisada em razão dos conflitos advindos dessa suposta divisão: parte de seus membros teriam interesses na difusão de transgênicos, e outra parte favoreceria os interesses dos ambientalistas.

Os interesses aparentes do jornal O Estado de S.Paulo se teriam alinhado às expectativas dos setores do governo favoráveis às liberações de transgênicos. Segundo o jornal, esse posicionamento representaria a política agrária oficial do governo Lula. Enquadramentos majoritários do jornal favoreceram posicionamentos do Ministério da Agricultura, Pecuária e Abastecimento em defesa da liberação da pesquisa e cultivo de OGMs. Os argumentos dos setores governamentais contrários aos organismos geneticamente modificados apareceram em menor proporção e, em alguns casos, foram enquadrados de maneira desfavorável. Isso justificaria por que o jornal cobriu a temática dos OGMs, majoritariamente, através de caderno dedicado à cobertura política. A Folha de S.Paulo, por sua vez, tendeu a caracterizar 
os OGMs como um avanço tecnológico que propiciaria o desenvolvimento econômico. O setor do agronegócio seria beneficiado pelo desenvolvimento dos transgênicos e, consequentemente, traria o crescimento econômico do país. Esses enquadramentos explicariam por que o jornal cobriu, principalmente, a temática dos transgênicos pelo caderno de Economia.

\section{Considerações finais}

A democracia digital está presente no cenário político atual como uma ferramenta capaz de minimizar uma suposta crise existente nas práticas democráticas e formas institucionais de representação política. A distância entre as esferas civil e política estaria assumindo grandes proporções, dificultando o aprofundamento da experiência democrática. Os mecanismos de consulta pública on line apresentam-se atualmente como uma contribuição para reverter o processo de erosão da legitimidade do processo democrático, ao permitir que a sociedade se expresse em novos canais sobre a formulação de políticas públicas. A participação, entretanto, deve ser sustentada por conhecimentos abrangentes, a fim de que a contribuição seja relevante. Os meios de comunicação, nesse contexto, revelam sua importância para a formação dos cidadãos e o esclarecimento de setores sociais, por meio da divulgação de informações sobre as mais variadas temáticas. A mídia pode contribuir para subsidiar a participação política, caso apresente pluralidade e equilíbrio em sua cobertura dos diversos temas.

A consulta pública on line da Anvisa esteve aberta entre julho e setembro de 2007, com o objetivo de receber contribuições à Proposta de Regulamento Técnico de avaliação de segurança para o consumo humano de alimentos contendo ou consistindo de organismo geneticamente modificado (OGM) e de alimentos contendo ou consistindo de produtos derivados de animais alimentados com OGM ou com seus produtos derivados. De acordo com o texto da consulta, seria preciso aperfeiçoar as ações de vigilância sanitária na área de alimentos, com o fim de proteger a saúde da população. A Anvisa teria o objetivo de expandir seus poderes sobre a deliberação de OGMs, função conferida à CTNBio pela Lei de Biossegurança. Os pedidos de liberação comercial de OGMs teriam de cumprir as etapas previstas no Regulamento Técnico antes da avaliação da Comissão e poderiam ser indeferidos caso não atendessem às exigências do questionário de 119 questões.

Os jornais Folha de S.Paulo e O Estado de S.Paulo construíram enquadramentos e agendas favoráveis aos transgênicos. Enquadramento é a construção simbólica que seleciona certos aspectos do fato ou acontecimento enfocado, enfatiza parte deles e exclui outros. A agenda é formada pelo conjunto de enquadramentos apresentados nas matérias, em certo período de tempo, que relacionam informações com a mesma temática.

A agenda de $60 \%$ dos textos informativos e $56,3 \%$ dos de gênero opinativo publicados na Folha de S.Paulo é favorável aos OGMs. O veículo apresentou conjuntos de enquadramentos que caracterizaram os transgênicos como benéficos para a humanidade, por serem melhores economicamente do que os tradicionais e considerados um avanço tecnológico capaz de minimizar problemas como a fome e a desnutrição. Órgãos que estariam tolhendo o desenvolvimento de organismos geneticamente modificados receberam 
enquadramentos negativos, a exemplo da CTNBio, que seria morosa na deliberação de pedidos de aprovação de cultivo de OGMs, e de ONGs contrárias aos transgênicos, caracterizadas como ideológicas e inimigas do progresso.

A agenda de $44 \%$ dos textos informativos e $80 \%$ dos opinativos publicados por $O$ Estado de S.Paulo também é favorável aos transgênicos. O jornal caracterizou majoritariamente os OGMs como benéficos para a saúde humana e a biodiversidade e eficientes economicamente, além de criticar órgãos que, supostamente, estariam atrapalhando seu desenvolvimento.

A análise dessas agendas permite sugerir que as principais perspectivas simbólicas veiculadas pelos jornais analisados, no período entre março de 2005 e setembro de 2007, caracterizam os transgênicos como benéficos à humanidade. Eles reduzem gastos, favorecem o crescimento da economia do país e podem multiplicar a produção sem que sejam aumentadas as áreas plantadas.

Espera-se que o jornalista busque isenção ao compor sua matéria. Mesmo assim, suas convicções e as posições de setores influentes sobre o corpo editorial de um jornal podem estar presentes em um texto, através dos enquadramentos ali adotados. A escolha das fontes também é uma maneira de o jornalista apresentar ideias que considera relevantes, sem se posicionar explicitamente sobre elas. A desvalorização de fontes provenientes de movimentos sociais foi percebida na amostra analisada. ONGs contrárias aos transgênicos receberam enquadramento desfavorável. Os jornais não apresentaram, por diversas vezes, representantes de ONGs como fontes de informação sobre a temática discutida.

Segundo Bourdieu (1999), as disputas simbólicas ocorrem em dois campos: diretamente entre as classes ou por meio dos especialistas do poder simbólico, como os jornalistas, com a utilização da violência simbólica legítima. Uma forma elementar de exercício de poder simbólico está na capacidade de 'nomeação' do campo político. Os jornais exerceram poder simbólico ao construir agendas favoráveis aos transgênicos. A maior parte das fontes entrevistadas foi composta por vozes oficiais, o que foi utilizado pelos veículos de comunicação como forma de nomeação do campo político. A publicação de editoriais também representa uma forma de violência simbólica legítima. Nesse cenário, a credibilidade apresentada pelo jornal perante seu público é direcionada para o enquadramento adotado nos textos de gênero opinativo.

A maior parte dos editoriais analisados mostrou-se favorável ao desenvolvimento dos transgênicos. Já os enquadramentos alinhados à agenda que sugere a existência de riscos no cultivo de OGMs correspondem a $20 \%$ dos textos informativos e a $21,7 \%$ dos opinativos publicados pelo jornal Folha de S.Paulo, e a 36\% dos textos informativos de O Estado de S.Paulo (ausentes dos textos opinativos desse veículo). Segundo essa agenda minoritária, os OGMs trariam riscos à saúde e à biodiversidade.

Considerando o total de 163 matérias analisadas, pode-se indicar que o conteúdo apresentado pelos principais jornais paulistas é, em geral, fragmentado, já que cerca de $70 \%$ das matérias não são suficientemente plurais e oferecem visões incompletas sobre o contexto da consulta pública. A formação propiciada pelos jornais sobre a temática dos transgênicos poderia colaborar em parte para subsidiar a participação política mais consis- 
tente de setores e indivíduos, mas seria necessário buscar informações que complementassem as lacunas deixadas pela cobertura dos veículos de comunicação estudados.

Houve certo equilíbrio, principalmente na cobertura do jornal O Estado de S.Paulo, entre o total de textos com enquadramentos favoráveis aos OGMs e o total de textos com enquadramentos em que os OGMs representariam riscos à saúde e à biodiversidade. No entanto, em ambos os jornais o que contribuiu para que a cobertura em geral contivesse lacunas sobre a temática em questão foi a ausência de textos mais equilibrados, que explorassem ambos os posicionamentos ao mesmo tempo, apresentando variados argumentos relevantes para o contexto da discussão em uma mesma abordagem.

Pode-se indicar que, mesmo com uma cobertura fragmentada e com tendência a enquadrar os OGMs de maneira favorável - o que confronta os princípios éticos de pluralidade e equilíbrio necessários ao jornalismo - a Folha de S.Paulo e O Estado de S.Paulo ofereceram subsídios relevantes à participação política. Mas, para que a participação em torno da consulta pública on line Anvisa 63 fosse embasada de maneira mais plural, abrangente e equilibrada, outras fontes de informação deveriam ser consultadas, tais como outros meios de comunicação, sítios governamentais, instrumentos de comunicação de empresas do setor e textos científicos. A identificação de enquadramentos e agendas destas fontes constitui um objetivo de grande importância, a ser explorado por pesquisas futuras.

\section{AGRADECIMENTOS}

Danilo Berbel agradece à Fundação de Amparo à Pesquisa do Estado de São Paulo (Fapesp) a bolsa de Iniciação Científica. Danilo Rothberg agradece ao Programa de Apoio a Projetos Institucionais com a Participação de Recém-Doutores (Prodoc), da Coordenação de Aperfeiçoamento de Pessoal de Nível Superior (Capes/Ministério da Educação), o apoio à pesquisa relacionada a este artigo.

\section{NOTAS}

${ }^{1}$ A Anvisa é uma autarquia criada pela lei 9.782, de 26 de janeiro de 1999, vinculada ao Ministério da Saúde, e exerce funções de agência reguladora do setor, caracterizada por independência administrativa, estabilidade de seus dirigentes durante o período de mandato e autonomia financeira.

${ }^{2}$ De acordo com o Mapa da Mídia, da Revista Imprensa (http://portalimprensa.uol.com.br/mapa), a Folha de S.Paulo liderava a circulação no estado em dias úteis, com 289.867 exemplares diários; em segundo, estava o jornal O Estado de S.Paulo, com 226.233 exemplares diários (dados de agosto de 2007).

${ }^{3}$ A pesquisa foi realizada com bolsa da modalidade de Iniciação Científica, concedida pela Fundação de Amparo à Pesquisa do Estado de São Paulo (Fapesp).

${ }^{4}$ A CTNBio é disciplinada pela lei 11.105, de 24 de março de 2005; segundo seu artigo 10, "integrante do Ministério da Ciência e Tecnologia, é instância colegiada multidisciplinar de caráter consultivo e deliberativo, para prestar apoio técnico e de assessoramento ao Governo Federal na formulação, atualização e implementação da PNB de OGM e seus derivados, bem como no estabelecimento de normas técnicas de segurança e de pareceres técnicos referentes à autorização para atividades que envolvam pesquisa e uso comercial de OGM e seus derivados, com base na avaliação de seu risco zoofitossanitário, à saúde humana e ao meio ambiente".

${ }^{5}$ Outras perspectivas identificadas na cobertura da Folha de S.Paulo (20\% dos textos informativos e $22 \%$ dos opinativos) e de O Estado de S.Paulo (20\% dos informativos) foram expressas isoladamente e não se inserem nessas tendências predominantes de enquadramento. Devido aos limites de espaço, elas não serão comentadas aqui.

${ }^{6}$ Conforme oportunamente informou um parecerista anônimo deste artigo, a CTNBio, entre setembro de 2007 e dezembro de 2008, aprovou a liberação comercial de seis variedades transgênicas de milho e uma de algodão. A relação de forças parece ter mudado no período subsequente ao analisado aqui, o que indica a necessidade de novas pesquisas para investigá-la. 


\section{REFERÊNCIAS}

AZEVEDO, Fernando Antônio.

Agendamento da política. In: Rubim, Antonio Albino Canelas (Ed.). Comunicação e política: conceitos e abordagens. São Paulo; Salvador: Unesp; EdUfba. p.41-71. 2004.

BASTOS, Alessandra.

Regulamento da Anvisa sobre transgênicos será documento consultivo. Disponível em: http:// www.agenciabrasil.gov.br/noticias/2007/08/10/ materia.2007-08-10.7612753426/view. Acesso em: 2 mar. 2009. 2007.

\section{BOURDIEU, Pierre.}

O poder simbólico. 3.ed. Rio de Janeiro: Bertrand Brasil. 1999.

CARRAGEE, Kevin M.; ROEFS, Wim.

The neglect of power in recent framing research. Journal of Communication, Washington D.C., v.54, n.2, p.214-233. 2004.

CORCUFF, Philippe.

As novas sociologias: construções da realidade social. Bauru: EdUsc. 2001.

DAVIES, Aeron.

Whither mass media and power?: evidence for a critical elite theory alternative. Media, Culture \& Society, v.25, n.5, p.669-690. 2002.

ENTMAN, Robert M.

Framing bias: media in the distribution of power. Journal of Communication, Washington D.C., v.57, n.1, p.163-173. 2007.

ENTMAN, Robert M.

Framing: toward clarification of a fractured paradigm. Journal of Communication, Washington D.C., v.43, n.4, p.51-58. 1993.
GOMES, Wilson.

A democracia digital e o problema da participação civil na decisão política. Fronteiras - Estudos Midiáticos, São Leopoldo, v.7, n.3, p.214-222. 2005.

HALL, Stuart.

Codificação/decodificação. In: Sovik, Liv (Org.). $\mathrm{Da}$ diáspora: identidades e mediações culturais. Belo Horizonte: Editora UFMG. 2003.

MARQUES, Francisco Paulo Jamil Almeida. Debates políticos na internet: a perspectiva da conversação civil. Opinião Pública, Campinas, v.12, n.1, p.164-187. 2006.

MIGUEL, Luis Felipe.

Modelos utópicos de comunicação de massa para a democracia. Comunicação \& Política, Rio de Janeiro, v.22, n.3, p.129-147. 2004.

PORTO, Mauro.

Enquadramentos da mídia. In: Rubim, Antonio A.C. (Org.). Comunicação e política: conceitos e abordagens. São Paulo: Unesp. 2004.

REESE, Stephen D.

The framing project: a bridging model for media research revised. Journal of Communication, Washington D.C., v.57, n.1, p.148-154. 2007.

ROTHBERG, Danilo.

Por uma agenda de pesquisa em democracia eletrônica. Opinião Pública, Campinas, v.14, n.1, p.149-172. 2008.

WOLF, Mauro.

Teorias das comunicações de massa. São Paulo: Martins Fontes. 2005.

\section{$\rightarrow \rightarrow \rightarrow<<<$}

